Article

\title{
Using Systems Thinking to Educate for Sustainability in a Business School
}

\author{
Amanda Gregory ${ }^{1} *$ and Susan Miller ${ }^{2}$ \\ 1 Business School, University of Hull, Hull, HU6 7RX, UK \\ 2 Business School, Durham University, Durham City, DH1 3LB, UK; \\ E-Mail: s.j.miller@durham.ac.uk
}

* Author to whom correspondence should be addressed; E-Mail: a.j.gregory@ @ull.ac.uk.

Received: 26 March 2014; in revised form: 18 June 2014 / Accepted: 20 June 2014 /

Published: 11 July 2014

\begin{abstract}
This paper explores what it means for a business school to embed systems thinking and sustainability into the curriculum by looking at both the application of systems thinking to the design of sustainable programmes and the teaching of system thinking to support understanding of sustainability. Although programmes that include systems thinking and sustainability as "bolt ons" are becoming more common, how these may best be integrated throughout the curriculum is still largely unexplored. In this paper, curriculum design is viewed through the lens of Stafford Beer's Viable System Model; viewing the management curriculum in this way emphasises the essential interconnectedness of the subject matter rather than its reduction into blocks of knowledge that are containable within standard size teaching modules. Merely recognising the interconnected nature of management knowledge does not go far enough, though, and there is a complementary need to equip students with approaches for describing more complex and pluralistic views of the world and to address such complexities. In this paper, the specification of a module, underpinned by Flood and Jackson's System of Systems Methodologies, that might serve to achieve these ends by introducing business students to a range of systems approaches is discussed. The challenges that realizing such an undertaking in practice might involve are also reflected on.
\end{abstract}

Keywords: systems thinking; sustainability; education; curriculum design; business schools 


\section{Introduction}

The debate about the role of business schools (used throughout this paper as a catch all term for deliverers of management education in the higher education sector) in society is a recurring one (see, for example [1,2]) and the recent financial crisis brought a new dimension to the debate $[3,4]$. As business schools educate the CEOs and managers of organizations that, through their operations, have effects that fundamentally impact on ecological, economic and social sustainability, it seems logical that the role of business schools should reflect a concern for sustainability in its broadest sense. Indeed, it has been suggested that ethics and sustainability should become core threads running through the curriculum in business schools [5] but there are "genuine concerns about business schools and their inability to come to terms with the sustainability agenda, despite different initiatives to nudge them towards that direction; society and social issues mean little or nothing in mainstream business education, which is unashamedly steeped in the narrow pursuit of economic performance" [6]. Cross-cultural theories of management might suggest that such an orientation is a consequence of the top ranking business journals all being published in the US and dominated by scholars based in the same country, and research into textbooks used in business schools also shows an Anglo-American dominance [7-9]. Consequently, notions of the transformational, achievement-oriented and personally rewarded leader abound while more systemic versions of management are scarcer; a popular, early exception being the work of Senge [10] on the learning organization. In the last five or so years, much work has been undertaken in the areas of responsible management education [11-14] and critical management education [15-19] although both are still largely represented in the curriculum as an alternative perspective or a beyond the mainstream view.

With relatively few exceptions, e.g., [20-24], systems thinking does not seem to have impacted on higher education in general and business schools and graduate schools of management in particular, despite it being well established [25-32] that systems thinking has much to contribute to sustainability discourses and applications. Increasingly, though, there is recognition that systems thinking provides a theoretical basis for discussions about sustainability and that both should command a place in the business school curriculum. Barter and Russell [33] analyse two key United Nations publications, Our Common Future [34] and the 25 year update of Resilient People: Resilient Planet [35], which, they argue, bring forward understanding of systemic thinking and responsible leadership. In highlighting "the key protagonists for enabling sustainable outcomes as business leaders and corporate strategists" who should "accept new responsibilities, as are congruent with an expanded understanding of the impact of organizational actions on a systemically interconnected world" [33], Barter and Russell place systems thinking prominently in the management education curriculum. In similar vein, Zsolnai et al. [36] redefine the roles and duties of management and management education to include, amongst other priorities, sustainability and holistic problem solving.

In light of the above, it may be surmised that, if business schools are to come to terms with the sustainability agenda, they need to embrace a more systemic perspective. Such a change would require a holistic understanding of the concept itself (there are many ways of being systemic) and also the questioning of what sustainability means from different perspectives. Indeed, Wals and Jickling [37] suggest that sustainability as a concept is "flawed" and that recognizing this is important since "Students must be in the position to examine critiques of scientism and technical rationality, and related life styles. 
If our universities and colleges do not facilitate this, then they basically fail to involve them in one of the biggest political challenges of our time" (p. 223). Hence, it is important to recognize that systems thinking and sustainability are both conceptually problematic and, consequently, to deeply embed such concepts in a business school curriculum is no easy challenge. If business schools are to really engage with this challenge then they need to understand systems thinking and sustainability in theory and practice by not only teaching about both but also applying the theory to their own operations.

This paper initiates an exploration of what it means for a business school to embed systems thinking and sustainability into the curriculum in a dynamic environment that is currently exploring what both mean. The focus is primarily on using systems thinking to understand and, if deemed desirable, achieve sustainability as it is assumed that the former is a necessary prerequisite for the latter. It is recognised that there are many aspects of "being systemic" that a business school might address but, given that the scope of this paper is already broad, some of these are, for pragmatic reasons, being regarded as beyond its scope. For example, it is recognized that the question of how business schools deliver is an important issue that impacts on sustainability but it falls outside the scope of this paper; although the work of Bawden et al. [38] on pedagogy is acknowledged as being particularly relevant. It is realized that this paper could be criticized for being too partial in focus while, at the same time, being criticized for being too ambitious in seeking to look at both the application of systems thinking to the design of programmes and the teaching of system thinking to support understanding of sustainability. It is believed that the two are too intimately entwined to focus on one and not the other and this should be evident if these concerns are summarily discussed:

- The design challenge

It is increasingly acknowledged that it is not sufficient to adopt a reductionist rationale to programme design and merely "bolt on" subjects in response to unfolding events [39]. This is particularly the case with respect to the teaching of ethics and sustainability where there is a need to inculcate a capacity in students to look holistically at business and ask questions about whether business is "doing the right things". Paul Danos, dean of Dartmouth College's Tuck School of Business, refers, in recognition of such a need, to the development of "deep courses where students are forced into that skeptical mindset of truly questioning..." [3]. Although programmes that infuse such thinking skills throughout the entire curriculum are becoming more common, how such integration may be achieved is still a largely underexplored area. In this paper, this issue is primarily viewed through a design lens although alternative lenses, such as the political, are considered highly relevant.

Business schools bring together academics from different disciplinary backgrounds ranging from the so-called "hard" disciplines [40] which seek to build knowledge cumulatively based on the scientific method, to the "soft" which are more focused on critiquing existing knowledge and paradigm plurality [41]. Non-specialist undergraduate business management programmes, postgraduate programmes such as the MBA, and masters in management which cover multiple functional areas of business are where such disciplines collide often resulting in a theoretical and political minefield which students, very often confused by the variety of different paradigm perspectives, are expected to negotiate. To be clear though, it is not merely a superficial truce, involving the artificial integration of different subject areas, that is required for the sake of simplicity; rather, the need to expose contrasting, even conflicting, perspectives, to recognise that even what counts as valid knowledge may be contested, and 
to do this in a way that is meaningful for both students and staff. Systems thinking has the potential to bring such understanding about but acceptance that systems thinking should have such an elevated position, some might argue, when space in the curriculum is hard won, not only with academic colleagues but also with students [42,43], is not easy to establish. Atwater et al. [21] reflect on this in terms of the systems archetype, the tragedy of the commons, with the limited resource being credit hours and recommend that systems be introduced in a required class early in the curriculum and students should then be encouraged or required to apply them in subsequent modules in other functional disciplines. A similar approach to Atwater et al. is suggested in this paper and this leads to the second issue of this paper, what to include in a module on systems thinking and how to embed learning from such a module throughout the curriculum.

- The curriculum content challenge

It has been argued that the nature of the business and management curriculum masks the essential interconnectedness of the subject matter [44], overemphasising the analysis of individual parts of firms at the expense of an appreciation of the integrative nature of organizational systems as a whole [45]. As a consequence of such a silo-based approach, there is a danger of the partial and narrow analyses of complex problems [46], amenable to simplistic solution-seeking. However it can be argued that simply recognising the messy systemic nature of problems [47] does not go far enough and it also needs to be acknowledged that such problems are open to multiple interpretations about their causes, consequences and possible solutions. The inclusion of systems thinking in the curriculum should enable students to move beyond questioning unitary interpretations and describing more complex and pluralistic views of the world, to enabling them to express their own personal concerns rooted in their local contexts and equip them with approaches to address such complexities.

Atwater et al. argue that "...people must be trained in the principles, concepts, and tools of systemic thinking in order to understand and work effectively with and within complex social systems." [21] (p. 13) and focus on causal loop mapping [48], a process whereby a visual representation is produced of how the variables in a system are connected, as an important approach in enabling understanding of how structure drives behavior. Such an approach is a particularly relevant technique when it comes to environmental management and sustainability but there is a wider range of systems approaches which are concerned with forms of complexity other than structural, such as economic, political and social complexity. Indeed, this wider range of approaches demand attention if Atwater et al.'s own ambition is to be realized and, in this paper, a module that serves to introduce business students to a range of systems approaches is described.

It should be clear from the above, that this is an exploratory paper and it is intended that the concerns that are raised will be the subject of further work. In the next section, discussion will be made of the use of viable system theory [49-51] for the design and management of curriculum content and an overview provided of a module on systems approaches.

\section{Utilizing Systems Thinking in Curriculum Design}

If the potential for systems thinking in the business school context is to be realized its practical utility needs to be demonstrated; curriculum design represents an opportunity to do this. Stafford Beer's [49-51] 
Viable System Model (VSM) is presented as a "thorough working out of ideas from the science of organisation, or cybernetics" [52] (p. 87) but can the VSM be meaningfully applied to programme design? Can programmes be designed to be sustainable learning systems in themselves, capable of responding to changes in their environments that could not be foreseen at the point of creation?

Figure 1. A programme portrayed as a viable system.

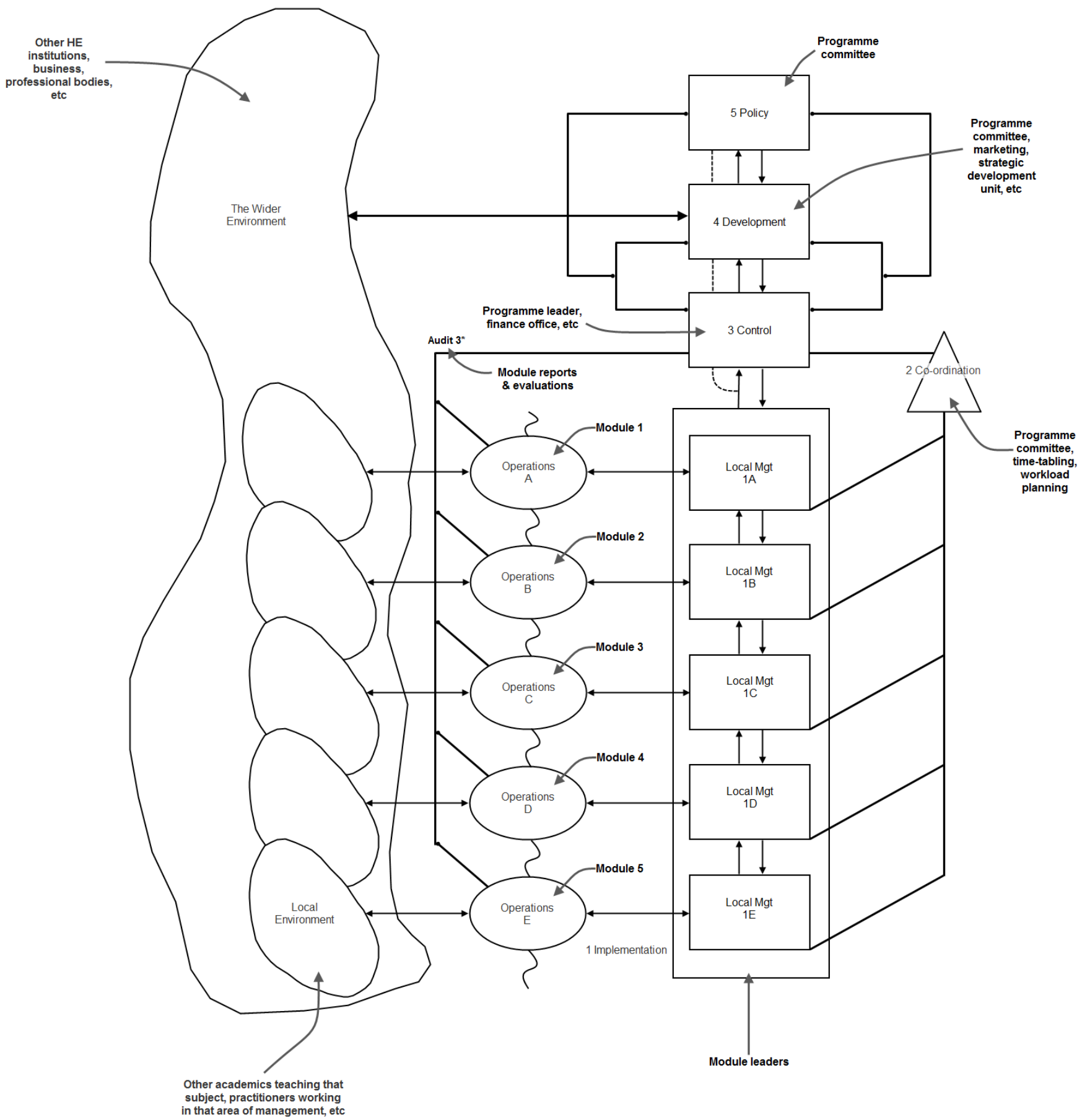

Programmes are multi-dimensional in nature and should be viewed holistically (as an emergent whole - the programme) rather than simply being seen as the sum of the parts (a collection of modules). A systems perspective acknowledges that one module will be limited in terms of what it enables students to see, but a programme that is informed by systems thinking should facilitate, through its 
design, students' ability to learn by reflecting on the links between the parts (modules) in order to better understand multi-dimensional issues, such as how to balance development with sustainability, that are beset with multiple interpretations. The conceptualization of a programme in this way focuses attention on how learning "spaces" [53] can be created in which both students and staff are encouraged to focus on the differences and links between modules.

The need for integrating mechanisms is not the only concern in programme design. The sustainability of programmes and their ability to remain relevant and current suggests a concern for content management particularly given the dynamic and changing nature of management knowledge. The logic of the VSM suggests that a programme should be viewed as a structure of unfolding complexity: with different levels of recursion, for example, from the university to the module level and each level absorbs variety from its local environment accordingly. This is important because the VSM is fundamentally based on the notion of maximum autonomy of the parts within the cohesive whole which in such an application is accommodating of dynamic and flexible approaches to content and teaching reflecting the different paradigmatic assumptions and approaches within subject areas.

Focussing at the programme level, the "system in focus", Figure 1 sets out the necessary functions (Systems 1 to 5 which are Operations, Co-ordination, Control, Development, and Policy) and communication flow/feedback loops between these:

- System 1, Operations, activities directly relate to the system's reason for being. In Figure 1 the Operations are the modules that make up the programme. Each of these has its own localized management or module leaders and own localized relations with the outside world (for example the accounting and finance module leader is expected to interact with practitioners and academics in that profession). The only restriction to the autonomy of System 1 (the module) is the requirement that it function as part of the whole (the programme) and the module leader would receive confirmation of their goals and objectives from System 5 (the programme committee), refined into targets (learning objectives), to ensure that they are complementary to the objectives of the wider systems (the programme and beyond) of which they are a part.

- To ensure that the modules are not destabilized by the others acting in a silo way (for example, duplication of content and balance of assessment methods) the modules are Co-ordinated by System 2 (multiple co-ordinating mechanisms including the informal, e.g., coffee shop chats between module leaders, and formal, e.g., programme committee meetings).

- The modules are intermittently subject to audit by System 3* (the programme leader) and routinely report on performance to System 3, Control, which is also responsible for reviewing budget proposals and allocating resources in accord with current policies and priorities.

- System 4, Development, brings together the programme leader, the marketing team and strategic development unit to synthesise internal information with information about the wider environment of the programme such as benchmarking against other institutions' offerings. System 4 must have a good grasp of what is going on internally if it is to capture relevant external information. If a rapid change or response is required then information is channeled to the Control function (programme leader) or if there is information that is longer term in nature then this goes to System 5, Policy (the programme committee). 
- System 5 formulates policy on the basis of information received from System 4 and communicates this downward through System 3 for implementation. System 5 (the programme leader representing the programme committee) must also articulate the identity and purposes of the programme to the wider system (the programme portfolio) of which it is a part.

It may be deduced from the above summary that the VSM balances a variety of competing pulls on any system; not only top-down versus bottom-up but also the internal demand for balance, System 3, with the outward and future oriented pulls expressed through System 4.

The above example demonstrates that it is possible to use the VSM as a heuristic device; to encourage critical thinking about how programmes and modules are designed and managed, especially:

- ensuring the appropriate engineering of variety [54] e.g., that the programme leader focus on information relevant to the whole and does not get overwhelmed by detail at the module level while giving autonomy to the parts (modules and their leaders) to ensure that decisions are taken at the most appropriate level;

- considering necessary co-ordination mechanisms, integrative spaces and information flows;

- establishing the distinctiveness of the programme through a strong awareness of the identity of the whole.

It is also worth noting that if a university has multiple campuses where it offers its programmes, perhaps at home and overseas, then it may also be useful to see System 1 parts as different locations in which the programme is offered as this ensures that attention is paid to local conditions/cultures.

\section{Systems Thinking as Curriculum Content}

In this section a module will be described which aims to educate business school students in the concepts, methodologies and commitments of systems thinkers in order that they might better understand and work effectively for sustainability with and within complex social systems themselves.

The content and form of such a module is driven by the definition of appropriate learning outcomes, such as to:

- promote the need for a systems approach through their reflection on important complex issues such as sustainability not only in theoretical terms but also their own experiences of "messes" [47];

- apply different systems methodologies and to be aware of their acceptability and utility in different contexts of application;

- appreciate the partiality of any approach.

In delivering such a module, attention would have to be given to providing a map of the systems terrain which enlightens rather than confuses; to this end, Jackson's [55] extended version of Jackson and Keys' [56] "system of systems methodologies" (SoSM) (see Figure 2) can be usefully employed. Such a simplified "map" is a useful teaching device at the start of such a module but once students get deeper into systems thinking its limitations become increasingly evident and they may be encouraged to critique it. The framework illustrates that problems cannot all be typified in the same terms and whilst it may be viewed as being able to contribute to real life problem solving it does not represent real life. 
Figure 2. A version of the system of systems methodologies with example approaches.

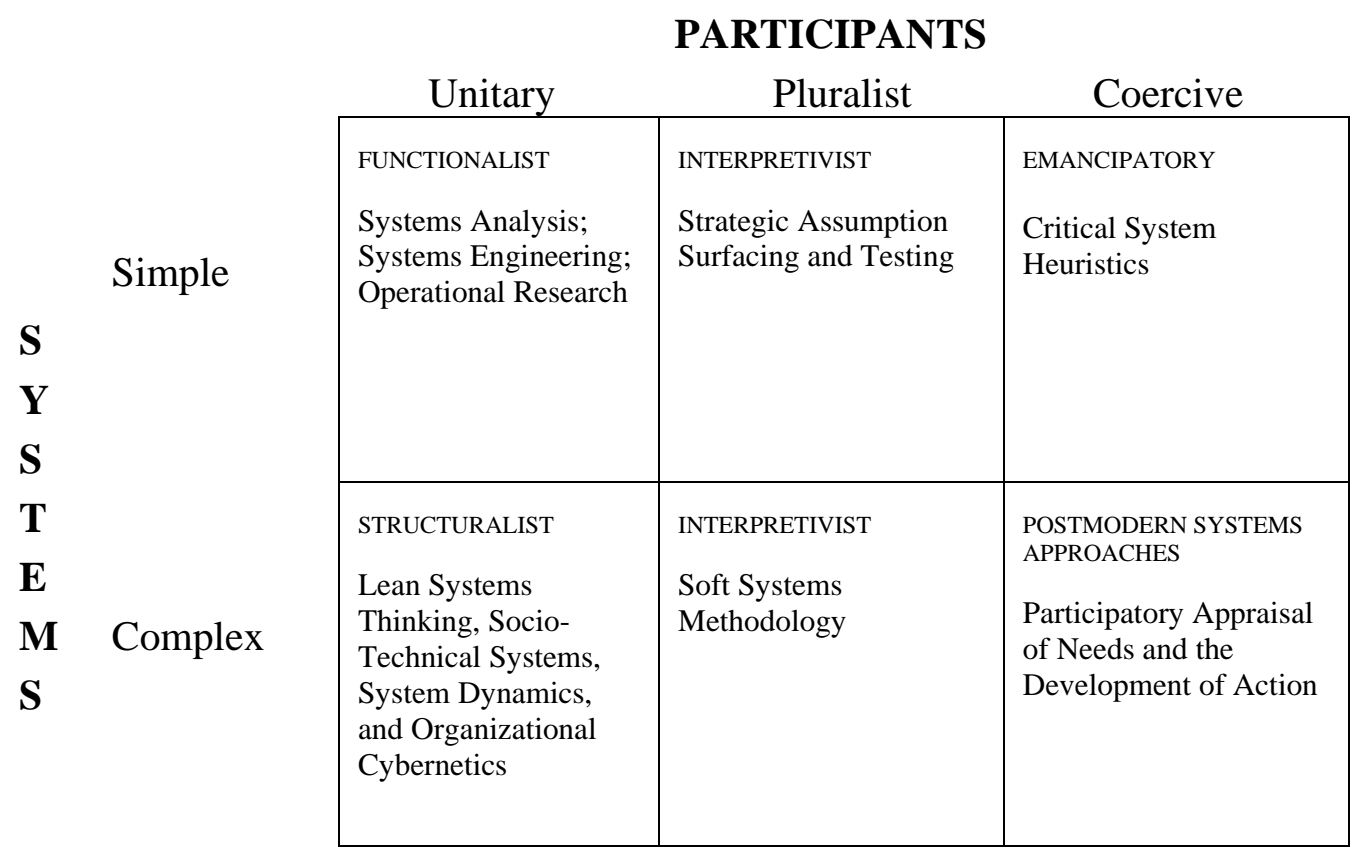

The SoSM enables the range of systems approaches, reflecting different paradigmatic underpinnings, to be appreciated and these are summarised here:

- The first attempts to apply systems ideas to problem solving began about the time of the Second World War, with approaches such as operational research, systems analysis and systems engineering (collectively referred to as the "hard systems approaches" reflecting their positivist underpinnings). These approaches may be useful in contexts where optimizing the effectiveness and efficiency in achieving agreed goals is paramount [55].

- Drawing heavily on Forrester's work on System Dynamics [57], Senge [10] presented Systems Thinking as an approach for enabling managers to understand how structure can drive system behaviour thus enabling managers to understand how a system comes to be in its present state (such an approach has been used to significant effect in public policy work, see for example, [58,59]).

- Lean Systems Thinking (LST), for example [60], focuses on eradicating failure demand and improving the ability of the system as a whole to enhance the customer experience. LST emphasises the need to create an evidence base and impetus for change by working through the stages of "check" (understand the organization as a system), "plan" (identify levers for change), and "do" (take direct action on the system).

- Strategic Assumption Surfacting and Testing (SAST) [61] relinquishes the functionalism of hard systems thinking for a more interpretivist orientation and the ill-structured nature of problem situation is explicitly recognised. SAST is concerned with "wicked problems" (characterised by interconnectivity, conflict, and uncertainty) debated from opposing perspectives and culminating in their resolution through a higher level of understanding.

- Critical Systems Heuristics (CSH) [62], following the work of Churchman [63], is concerned with identifying and addressing organizational and societal inequities brought about through the exclusion of certain stakeholders from decision making processes. The value assumptions which 
lead to such exclusionary behaviour are often presented as given hence CSH seeks to expose them to question. Thus, this approach offers a more critical and potentially emancipatory perspective.

- Participatory Appraisal of Needs and the Development of Action (PANDA), Taket and White [64] established the nature of intervention in postmodern form. This approach emphasises multiple interpretations of the world, being tolerant of difference and the importance of being responsive to what is achievable at the local level.

Merely having a good understanding of the systems methodologies is necessary but not sufficient for good systems practice as developing a deep appreciation of the underpinning philosophy, encapsulated in three commitments [55], is equally, perhaps more, important:

- critical awareness relates to the critique of the different systems methodologies and social awareness of the societal and organizational context;

- improvement relates to the achievement of "something beneficial" reflecting a circumspect aspiration in the light of the postmodernist challenge to the notion of universal liberation;

- pluralism recognizes the need to work with multiple paradigms without recourse to some artificial "unifying" metatheory; the ability to use methods disconnected from the paradigm of their genesis but with an awareness of the paradigm that they are being used to serve, and the existence of other ways of being pluralistic, for example Mingers and Brocklesby's multi-methodology [65].

To become systems thinkers requires students to not only understand the commitments but also to be able to practise them when studying other disciplines and also in their own contexts. Such a requirement is similar to that addressed by Giving Voice to Values (GVV) pedagogy [66-73] and learning may be derived from this. The focus of GVV is essentially systemic with faculty members "guiding a discussion of feasible applications of the core principles of their respective disciplines and on knowing how to act in a responsible way in a given context" [73] (p. 59). Such a focus is similar to that of Grey, Knights and Willmott [74] (p. 100) who argue that a critical approach should start with the students' own lived experience and this might be regarded as fundamental to the design of the assessment on any systems-based module or programme. Schwandt's work on integrating learning with sensemaking [75] (p. 189) may be drawn on in requiring students to describe their own problem situations, which forces them to reflect on their experience of complexity. Given the multicultural nature of the student body of many business schools, much may be learnt through this process of reflection about the practical applicability of systems methodologies in different contexts. For example, a group might question whether rich pictures, a technique used in Soft Systems Methodology [76,77], would be acceptable in religions that declare that there should be no portrayal of a person's image.

In describing their own situations, students are required to think about what they are prioritising and what they are down-playing in order to justify their choice of methodology (of course, theoretically this might be done through the SoSM). Although such a form of module assessment may focus on the application in detail of one systems methodology, it also gives students the opportunity to recognize that once they have used a methodology there may be a need to shift to another; enabling understanding of the demands of complexity and pluralism to be demonstrated. Systems thinking sees value in all the different developed and emerging systems approaches, viewing them as a complementary set, capable of being used in combination to address the real world complexity, heterogeneity, ambiguity and 
paradox that means that no one approach alone is sufficient to address. A multi-methodogical approach is advocated to cope with complexity that is inevitable when addressing grand challenge issues such as sustainability. Such an approach therefore utilizes a variety of developed and emerging systems approaches and methodologies that are based on opposing paradigms. The contradictory nature of their underlying philosophical assumptions means that they cannot simply be integrated so the approach seeks to manage paradigm diversity by encouraging them to confront one another on the basis of "reflective conversation" [78,79]. No methodology is allowed to escape unquestioned because it is continually confronted by the alternative rationales offered by others. The preferred way of working [80] is to observe a continuous commitment to methodological pluralism by working with "dominant" and "dependent" methodologies in creative combination. For example, CSH and SSM might be used in a complementary and iterative way to decide, firstly, who ought to be involved in a particular intervention and to bring that group together to explore the problem situation and, secondly, this might then involve further boundary critique and questioning of who ought be involved as SSM supports stakeholders in seeing different parts of the problem situation. Pollack [81] calls this a "parallel" approach to multi-methodology as opposed to a "serial" approach. Working with seemingly incommensurable methodologies in this way ( $\mathrm{CSH}$ having emancipatory underpinnings which contrast to the interpretivist underpinnings of SSM) goes some way towards mirroring the challenges of paradox and contradiction inherent in the messy and multi-faceted problems of the real world and using a range of theoretical perspectives to reflect on practice. There is a rich stream of literature that provides useful instruction on the challenges that such a critical form of systems thinking and practice brings (see for example, $[82,83])$.

\section{Reflections}

"A significant obstacle to sustainability becoming more embedded into the business school ethos is that a major mind-shift away from academic traditions is required for this to become a reality" [6].

The idea that accepted dominant modes of thought and practice should be challenged is central to a systems approach. Embedding a systemic approach in the curriculum represents an opportunity to not only challenge students to be critical but also for faculty to challenge themselves to be critical about being critical (following [84,85]). How far are faculty prepared to be critical of their own academic paradigm and associated practices? The process of questioning what is acceptable may lead to far greater awareness of where the boundaries lie, what is amenable to change and what is not, which highlights the relevance of the political lens. Such considerations extend beyond the local faculty context to, in the UK, the external examiner (an academic at another institution who is responsible for assuring the academic quality of a module or programme) and professional accrediting bodies who can be either a major facilitator of or impediment to change. It is intended that further work will look through a political lens at the issue of how negotiations are managed about what is regarded as relevant knowledge for inclusion in the business school curriculum and the consequent inclusion, or not, of sustainability and systems thinking. 


\section{Conclusions}

In this paper, the argument was advanced that sustainability and systems thinking must be regarded to be a complementary set; concern for one without the other is necessary but not sufficient. Systems theory provides the theoretical basis for discussions about sustainability and sustainability provides an important concern of practical relevance for systems thinking. To understand the implications of embedding either in the curriculum is no small feat and it is necessary to not merely seek to "bolt on" these subjects to the curriculum but rather to apply the logic of both to our own endeavors. This paper initiated such an undertaking by exploring what it means for a business school to promote a concern for the sustainability of programmes through the application of systems thinking to their design. In this paper, curriculum design was viewed through the lens of the VSM. Viewing the management curriculum in this way, emphasises the essential interconnectedness of the subject matter rather than the reduction of the curriculum into blocks of knowledge that are containable within standardized teaching modules. Merely recognising the messy systemic nature of management knowledge does not go far enough, though, and it was recognized that there is an associated need to equip students with approaches for describing more complex and pluralistic views of the world, and enable them to address such complexities. In this paper, the specification of a module that serves to introduce business students to a range of systems approaches was described. Learning from such a systems module might feasibly be enthused throughout an entire programme as it is carried through to other modules by requiring students to view the functional areas of management in holistic terms. It is recognized that the recommendation for systems thinking to occupy such an elevated position in the curriculum heralds a mind-shift, and although programmes that include systems thinking in the curriculum are becoming more common, programmes that infuse systems thinking throughout the curriculum are still rare and how this might best be achieved is still largely unexplored. Finally, it was proposed that, if a more holistic and searching approach to business and management issues is to be achieved, it is necessary that the negotiation between faculty, students and other stakeholders, such as those responsible for ensuring the quality of management education programmes, be viewed through a political lens as such negotiations focus on the question of what is regarded as valuable knowledge and what is not. In conclusion, this paper takes up the challenge of addressing what is required for a concern for systems thinking and sustainability to be embedded in business schools; as a result of this exploration it should be recognized that this is a grand challenge that needs to be pursued, to quote Churchman [63], in a collective "heroic mood".

\section{Acknowledgments}

The authors would like to express their gratitude to the guest editors of this special issue of Systems and the reviewers who provided very helpful constructive feedback on earlier drafts of this paper. We would also like to thank Grace Lu for her patience and support.

\section{Author Contributions}

Both authors contributed equally to the initial development of ideas and thinking in relation to the paper. Amanda Gregory then worked on the development of the paper with Sue Miller commenting on drafts which gave led to the further elaboration of key arguments expressed in the paper. 


\section{Conflict of Interest}

The authors declare no conflict of interest.

\section{References}

1. Mintzberg, H. Managers not MBAs; Berrett-Koehler Publishers: San Francisco, CA, USA, 2004.

2. Cornuel, E. The role of business schools in society. J. Manag. Dev. 2005, 24, 819-829.

3. The Economist. How do Business Schools Remain Relevant in Today's Changing World? 1 December 2009. Available online: http://www.economist.com/node/15006681 (accessed on 26th June 2014).

4. Podolny, J.M. The buck stops (and starts) at business school. Harv. Bus. Rev. 2009, 87, 62-67.

5. Rayment, J.; Smith, J. The current and future role of business schools. Education + Training 2013, 55, 478-494.

6. The Guardian. Business Schools: "The Silent but Fatal Barrier to the Sustainability Agenda". 13 March 2014. Available online: http://www.theguardian.com/sustainable-business/business-schoolsdeadly-sustainability-agenda (accessed on 15th May 2014).

7. Engwall, L. The anatomy of management education. Scand. J. Manag. 2007, 23, 4-35.

8. Fougère, M.; Moulettes, A. Disclaimers, dichotomies and disappearances in international business textbooks: A postcolonial deconstruction. Manag. Learn. 2012, 43, 5-24.

9. Engwall, L. Foreign role models and standardisation in Nordic business education. Scand. $J$. Manag. 2000, 15, 1-24.

10. Senge, P.M. The Fifth Discipline. The Art and Practice of the Learning Organization; Century Business: London, UK, 1990.

11. UN Global Compact. The Principles for Responsible Management Education. 2007. Available online: http://www.unprme.org/resource-docs/prme.pdf (accessed on 26 March 2014).

12. Rabasso, C.A.; Rabasso, J. A Chomskyan approach to responsible critical management education. J. Global Responsib. 2010, 1, 66-84.

13. Kaul, M.; Smith, J. Exploring the nature of responsibility in higher education. J. Global Responsib. 2012, 3, 134-150.

14. Wilcox, T.; Sheldon P.; Wardrop. J. A capabilities approach to curriculum design: Developing responsible business professionalism. Int. Rev. Bus. Res. 2012, 8, 107-117.

15. Alvesson, M.; Willmott, H. Critical Management Studies; Sage: London, UK, 1992.

16. Clegg, S.; Kornberger, M.; Carter, C.; Rhodes, C. For management? Manag. Learn. 2006, 37, 7-27.

17. Spicer, A.; Alvesson, M.; Kärreman, D. Critical performativity: The unfinished business of critical management studies. Hum. Relat. 2009, 62, 537-560.

18. Clegg, S.; Dany, F.; Grey, C. Special issue critical management studies and managerial education: New contexts? New agenda? Management 2011, 14, 271-279.

19. Alvesson, M.; Spicer, A. Critical leadership studies: The case for critical performativity. Hum. Relat. 2012, 65, 367-390.

20. Bui, H.T.M.; Baruch, Y. Learning organizations in higher education: An empirical evaluation within an international context. Manag. Learn. 2012, 43, 515-544. 
21. Atwater, B.J.; Kannan, V.R.; Stephen, A.A. Cultivating systemic thinking in the next generation of business leaders. Acad. Manag. Learn. Educ. 2008, 7, 9-25.

22. Atwater, B.J.; Pittman, P.H. Facilitating systemic thinking in business classes. Decis. Sci. J. Innovat. Educ. 2006, 4, 273-292.

23. Waddock, S. Finding wisdom within: The role of seeing and reflective practice in developing moral imagination, aesthetic sensibility, and systems understanding. J. Bus. Ethics Educ. 2011, 7 , 177-196.

24. Werhane, P.H. Mental models, moral imagination and system thinking in the age of globalization. J. Bus. Ethics. 2008, 78, 463-474.

25. Capra, F. The Web of Life-A New Synthesis of Mind and Matter; Harper Collins: London, UK, 1996.

26. Capra, F. The Hidden Connections: A Science for Sustainable Living; Harper Collins: London, UK, 2003.

27. Gregory, A.J.; Atkins, J.; Burdon, D.; Elliott, M. A problem structuring Method for eco-system based management: The DPSIR framework. Eur. J. Oper. Res. 2013, 227, 558-569.

28. Ison, R. Systems Practice: How to Act in a Climate Change World; Springer: London, UK, 2010.

29. Midgley, G.; Reynolds, M. Systems/operational research and sustainable development: Towards a new agenda. Sustain. Dev. 2004, 12, 56-64.

30. Nguyen, N.C.; Graham, D.; Ross, H.; Maani, K.; Bosch, O. Educating systems thinking for sustainability: Experience with a developing country. Syst. Res. Behav. Sci. 2012, 29, 14-29.

31. Nguyen, N.C.; Bosch, O.J.H. A systems thinking approach to identify leverage points for sustainability: A case study in the Cat Ba Biosphere Reserve, Vietnam. Syst. Res. Behav. Sci. 2013, 30, 104-115.

32. Paucar-Caceres, A.; Espinosa, A. Management science methodologies in environmental management and sustainability: Discourses and applications. J. Oper. Res. Soc. 2011, 62, 1601-1620.

33. Barter, N.; Russell, S. Two snapshots reinforcing systemic thinking and responsibility. J. Global Responsib. 2014, 5, 45-54.

34. World Commission on Environment and Development. Our Common Future; Oxford University Press: Oxford, UK, 1987.

35. United Nations Secretary-General's High Level Panel on Global Sustainability. In Resilient People, Resilient Planet: A Future Worth Choosing; United Nations: New York, NY, USA, 2012.

36. Zsolnai, L.; Junghagen, S.; Tencati, A. Redefining the roles and duties of management. J. Global Responsib. 2012, 3, 121-133.

37. Wals, A.E.J.; Jickling, B. "Sustainability" in higher education: From doublethink and newspeak to critical thinking and managingful learning. Int. J. Sustain. High. Educ. 2002, 3, 221-232.

38. Bawden, R.; McKenzie, B.; Packham, R. Moving beyond the academy: A commentary on extra-mural initiatives in systemic development. Syst. Res. Behav. Sci. 2007, 24, 129-141.

39. Arkin, A. School for Scandal. In People Management; CIPD: London, UK, 2013.

40. Neumann, R.; Parry, S.; Becher, T. Teaching and learning in their disciplinary contexts: A conceptual analysis. Stud. High. Educ. 2002, 27, 406-417.

41. Lattuca, L.; Stark, J. Will disciplinary perspectives impede curricular reform? J. High. Educ. 1994, 65, 401-426. 
42. Thompson, T.A.; Purdy, J.M. When a good idea isn't enough. Curricular innovation as a political process. Acad. Manag. Learn. Educ. 2009, 8, 188-207.

43. Rubin, R.S.; Dierdorff, E.C. On the road to abilene: Time to manage agreement about MBA curricular relevance. Acad. Manag. Learn. Educ. 2011, 10, 148-161.

44. Pfeffer, J.; Fong, C.T. The end of business schools? Less success than meets the eye. Acad. Manag. Learn. Educ. 2002, 1, 78-95.

45. Zald, M.N. Spinning disciplines: Critical management studies in the context of the transformation of management education. Organization 2002, 9, 365-385.

46. Ghoshal, S. Bad management theories are destroying good management practice. Acad. Manag. Learn. Educ. 2005, 4, 75-91.

47. Ackoff, R.L. The art and science of mess management. Interfaces 1981, 11, 20-26.

48. Maani, K.E.; Cavana, R.Y. Systems Thinking, System Dynamics: Managing Change and Complexity, 2nd ed.; Pearson Education NZ: Auckland, New Zealand, 2007.

49. Beer, S. Heart of Enterprise; Wiley: Chichester, UK, 1979.

50. Beer, S. Brain of the Firm, 2nd ed.; Wiley: Chichester, UK, 1981.

51. Beer, S. Diagnosing the System for Organizations; Wiley: Chichester, UK, 1985.

52. Flood, R.L.; Jackson, M.C. Creative Problem Solving: Total Systems Intervention; Wiley: Chichester, UK, 1991.

53. Beyes, T.; Michels, C. The production of educational space: Heterotopia and the business school. Manag. Learn. 2011, 42, 521-536.

54. Ashby, W.R. An Introduction to Cybernetics; Methuen: London, UK, 1956.

55. Jackson, M.C. Systems Approaches to Management; Kluwer/Plenum: London, UK, 2000.

56. Jackson, M.C.; Keys, P. Towards a system of systems methodologies. J. Oper. Res. Soc. 1984, 35, 473-486.

57. Forrester, J.W. Industrial Dynamics; MIT Press: Cambridge, MA, USA, 1961.

58. Cavana, R.Y.; Clifford, L.V. Demonstrating the utility of system dynamics for public policy analysis in New Zealand: The case of excise tax policy on tobacco. Syst. Dynam. Rev. 2006, 22, 321-348.

59. Munro Review of Child Protection Part One: A Systems Analysis; Department for Education: London, UK, 2010.

60. Seddon, J. Freedom from Command and Control: A Better Way to Make the Work Work; Vanguard Education Ltd.: Buckingham, UK, 2003.

61. Mason, R.O.; Mitroff, I.I. Challenging Strategic Planning Assumptions; John Wiley and Sons: Chichester, UK, 1981.

62. Ulrich, W. Critical Heuristics of Social Planning; Haupt: Bern, Switzerland, 1983.

63. Churchman, C.W. The Systems Approach; Delta Books: New York, NY, USA, 1968 (reprinted 1979).

64. Taket, A.; White, L. Partnership and Participation: Decision-Making in the Multiagency Setting; Wiley: Chichester, UK, 2000.

65. Mingers, J.; Brocklesby, J. Multimethodology: Towards a framework for mixing methodologies. Omega 1997, 25, 489-509.

66. Gentile, M.C. A faculty forum on giving voice to values: Faculty perspectives on the uses of this pedagogy and curriculum for values-driven leadership. J. Bus. Ethics Educ. 2011, 8, 305-307. 
67. Chappell, S.; Webb, D.; Edwards, M. A required GVV ethics course: Conscripting ethical conversations. J. Bus. Ethics Educ. 2011, 8, 308-319.

68. Warnell, J. "Ask more" of business education: Giving voice to values for emerging leaders. J. Bus. Ethics Educ. 2011, 8, 320-325.

69. Trefalt, S. Integrating giving voice to values across the MBA curriculum: The case of Simmons School of Management. J. Bus. Ethics Educ. 2011, 8, 326-331.

70. Stumpf, S.A. Engaging MBAs in voicing values through peer coaching. J. Bus. Ethics Educ. 2011, 8, 332-336.

71. Arce, D.G. Giving voice to values in economics and finance. J. Bus. Ethics Educ. 2011, 8, 343-347.

72. Adkins, C.P. A pathway for educating moral intuition: Experiential learning within the giving voice to values curriculum. J. Bus. Ethics Educ. 2011, 8, 383-391.

73. Gentile, M. The holy grail: Educating for values-driven leadership across the curriculum and giving voice to values. Global Focus. 2014, 8, 56-59.

74. Grey, C.; Knights, D.; Willmott, H. Is a Critical Pedagogy of Management Possible? In Rethinking Management Education; French, R., Grey, C., Eds.; Sage: London, UK, 1996.

75. Schwandt, D.R. When managers become philosophers: Integrating learning with sensemaking. Acad. Manag. Learn. Educ. 2005, 4, 176-192.

76. Checkland, P.B. Systems Thinking, Systems Practice; Wiley: Chichester, UK, 1981.

77. Checkland, P.; Poulter, J. Learning for Action: A Short Definitive Account of Soft Systems Methodology and its Use, for Practitioners, Teachers and Students; John Wiley and Sons: Chichester, UK, 2006.

78. Gregory, W.J. Discordant pluralism: A new strategy for critical systems thinking? Syst. Pract. 1996, 9, 605-625.

79. Jackson, M.C. Systems Thinking: Creative Holism for Managers; Wiley: Chichester, UK, 2003.

80. Jackson, M.C. Towards coherent pluralism in management science. J. Oper. Res. Soc. 1999, 50, 12-23.

81. Pollack, J. Multimethodology in series and parallel: Strategic planning using hard and soft OR. J. Oper. Res. Soc. 2009, 60, 156-167.

82. Brocklesby, J. Becoming Multi-Methodology Literate: An Assessment of the Cognitive Difficulties of Working Across Paradigms. In MultiMethodology-The Theory and Practice of Combining Management Science Methodologies; Mingers. J., Gill, A., Eds.; Wiley: Chichester, UK, 1997; pp. 189-216.

83. Midgley, G. Systemic Intervention: Philosophy, Methodology, and Practice; Kluwer/Plenum: New York, NY, USA, 2000.

84. Mingers, J. What is it to be critical? Teaching a critical approach to management undergraduates. Manag. Learn. 2000, 31, 219-237.

85. Reynolds, M. Reflection and critical reflection in management learning. Manag. Learn. 1998, 29, 183-200.

(C) 2014 by the authors; licensee MDPI, Basel, Switzerland. This article is an open access article distributed under the terms and conditions of the Creative Commons Attribution license (http://creativecommons.org/licenses/by/3.0/). 